Article

\title{
Conductive Coatings of Cotton Fabric Consisting of Carbonized Charcoal for E-Textile
}

\author{
Esubalew Kasaw, Adane Haile and Melkie Getnet * \\ Textile Chemistry Research and Innovation Center, Ethiopian Institute of Textile and Fashion Technology, \\ Bahir Dar University, Bahir Dar 1037, Ethiopia; Esubalew.Kasaw@bdu.edu.et (E.K.); \\ Adane.Haile@bdu.edu.et (A.H.) \\ * Correspondence: melkie.getnet@bdu.edu.et or melkiegetnet23@gmail.com; Tel.: +251-991-623766
}

Received: 28 May 2020; Accepted: 19 June 2020; Published: 21 June 2020

\begin{abstract}
Development of smart textiles is an emerging discipline in the last two decades where a conductive element is integrated into a textile material by some means. The purpose of this research was to develop a conductive textile fabric by coating with charcoal as a conductive element. The charcoal was produced by carbonizing the eucalyptus wood at a temperature of $928{ }^{\circ} \mathrm{C}$ for $37 \mathrm{~min}$ producing $59.17 \% \mathrm{w} / \mathrm{w}$ of fixed carbon yield and conductivity of $463.34 \mathrm{Sm}^{-1}$ (Siemens per meter) compared to immeasurable conductivity of the wood. This was followed by characterization of physical and chemical properties of charcoal. Thereafter, a cotton fabric was pad-coated with a dispersion based on the charcoal. The paper herein reports the results of preparing different recipes using different quantities of charcoal particles with other components of the coating mixture, which was tested to obtain the best coating in terms of electrical conductivity. The optimal concentration of the conductive particles of the charcoal was studied. Performance evaluation of the coated fabric was assessed for the durability of fabric towards different fastness agents. The effect of charcoal loading on thermal and sensorial comfort of the fabric in addition to the air and water permeability was studied and a significant change was observed. Finally, a proof of concept was developed to demonstrate if the resulting pieces of information during the process were viable. As observed, the pad-coated cotton fabric using charcoal showed increased electrical conductivity from $1.58 \times 10^{-12} \mathrm{Scm}^{-1}$ (Siemens per centimeter) for the controlled sample to $124.49 \mathrm{Scm}^{-1}$ for the coated sample designating that the resulting fabric is in a conductor category.
\end{abstract}

Keywords: carbonization; resistance; conductive fabric; coating; performance evaluation

\section{Introduction}

In the last two decades, e-textiles, including conductive textiles have gained great attention from many researchers due to their widespread applications in biomedical devices, sensing and actuating, data processing and communication, energy conversion and storage, electromagnetic shielding, etc. [1]. Electrical conductivity is the main requirement for smart and electronic textiles in addition to lightweight property, flexibility and ease of use. Textile materials like cotton fabric have very low electrical conductivity with a typical surface resistivity of $10^{7}-10^{16} \Omega / \mathrm{m}^{2}$ [2], which can be considered as low conductive materials. Thus, making textile materials can be a research direction in the materials science arena. There are several options to make textile materials electrically conductive. By making textile materials electrically conductive, it is possible to replace metal fibers in the form of thin metal filaments that were used previously, which are brittle, heavier and more difficult to process than conventional textile fibers [1]. Besides, metals have high environmental effect during their synthesis to fiber and their disposal has a polluting effect $[1,3]$. The coating of textile fibers and fabrics with metallic salts has also been used as another option, but these have limited stability during laundering [4]. 
Some people were using different allotropes of carbons such as graphene [2], carbon black [5] and carbon nanotube [6] to enhance the conductivity of fabric. The level of conductivity of carbon-based coating depend on the purity of carbon [7], degree of loading [5] and degree of dispersion [8] and percolation thresholds [9]. The development of intrinsically conductive polymers has opened up new possibilities for electrically conductive textile materials [10-12]. These polymers are conjugated polymers in which electrical conductivity is dramatically increased by means of doping. The doping agent removes the hydrophilic non-conductive parts of the polymer by forming extra bonds with it. That means, in doping, a small amount of chemical agent has been added, and the electronic structure is changed so that the electrical conductivity enhanced. However, the doping process is reversible and involves a redox process $[13,14]$. Conductive polymers are available as solid compounds or liquid dispersions or solutions. The liquid versions can easily be applied on to the textile substrate by coating method [15-18]. Textiles have been frequently coated and printed to get different surface functional properties, of which electrical conductivity gains significance interest for smart textiles application [19], and surface properties have been characterized. However, there have not been in-depth investigations in the possibilities of applying conductive coatings on the textile by similar methods as used in the textile industry. While this seems straightforward, several technical obstacles must be challenged to realize the successful application of conductive materials.

In the present paper, the possibilities of obtaining conductive surfaces on textile fabrics by the pad-dry-cure method with dispersion containing charcoal particles in a similar manner used in the textile industry was studied. The resulting fabric was expected to be conductive enough to be efficient for signal transport in the course of the development of the smart textiles. To do that, eucalyptus wood was carbonized by varying time and temperature to find an optimum conductivity of the produced charcoal. Then, a dispersion based on charcoal particles was prepared and applied on to the cotton fabric in the pad-dry-cure process followed by oven drying and curing. The electrical conductivity of the charcoal-coated cotton fabric was then measured. In addition, the tensile strength, tactile comfort and the thermal properties of the coated fabric were also assessed. An acceptable conductivity was achieved through the said method.

\section{Materials and Methods}

\subsection{Materials, Reagents and Chemicals}

\subsubsection{Fabric}

Half bleached cotton fabric with $21 \mathrm{Ne}, 28$ ends per centimeter and 32 picks per centimeter and 147 gram per square meter were obtained from Bahir Dar Textile Share Company, Bahir Dar, Ethiopia.

\subsubsection{Wood}

Eucalyptus wood with an age of 3.5 years was collected from Abaymado, Bahir Dar, Ethiopia. Different parts of the eucalyptus tree like branches, leaves, annual rings, pitches and barks were separated for further procedure. Separated components were then air-dried for fifteen days. The annual ring and pitch were the parts carbonized in the current study.

\subsubsection{Chemicals}

Charcoal was carbonized from eucalyptus wood. Ethanol (purity $99 \%$ ) was employed to facilitate sonication of charcoal particles in water. 1,2,3,4-Butane tetracarboxylic acid (BTCA; purity 98\%) with magnesium chloride as a catalyst assistant $\left(\mathrm{MgCl}_{2}\right)$ was used as a fixing agent for the pad coating method. Throughout the formulation of charcoal dispersion, a commercial-grade dispersant was used to ensure uniform dispensability of charcoal. Each analytical grade chemicals were bought from the market and used as received. 


\subsection{Experimental Procedures}

\subsubsection{Carbonization of Eucalyptus Wood}

Charcoal was prepared by carbonization of eucalyptus wood using a muffle furnace (model-48000) based on the ASTM D 1762-84 test method [20], chemical analysis of wood charcaol. The ASTM method was modified only by the employed time and temperature. Samples were carbonized at different temperature and time under $20^{\circ} \mathrm{C} \mathrm{min}^{-1}$ heating rate. To do that, the air-dried annual ring and pitch parts of eucalyptus wood pieces were put into a stainless-steel retort and placed in a muffle furnace that can maintain the predefined carbonization temperatures as per the experimental design by central composite design using Design expert 11 as shown in Table 1. The container was kept in the furnace for $30 \mathrm{~min}$ after carbonization as cooling time.

\subsubsection{Characterization of Eucalyptus Wood Charcoal}

The proximate analysis was performed employing muffle furnace Model-48000. The analysis was carried out following ASTM E871-82 [21] for moisture content, ASTM E872-82 [22] for volatile organic matter and ASTM D1102-84 [23] for ash content. The fixed carbon content was determined from the percentage as described in Equation (1).

$$
\% \text { Fixed carbon, } F C=100-(\% \text { moisture }+\% \text { volatile matter }+\% a \text { ash })
$$

To evaluate the efficiency of the wood carbonization process, the carbonization yield was calculated as described in Equation (2). It represents the percentage of a dry eucalyptus that remains in the solid product after carbonization under given conditions as shown in Table 1.

$$
\text { Yield }(\%), Y=\frac{\left(w_{1-}-w_{2}\right)}{w_{1}} \times 100
$$

where $w_{2}$ is the dry mass of charcoal produced by carbonization of dry eucalyptus wood $\left(w_{1}\right)$.

However, charcoal contains complex organic chemical compounds and inorganic species and the charcoal yield gives a rather poor-quality indication. For the charcoal to be used as a conductor, its fixed carbon content is the most important quality to be taken into account and calculated as described in Equation (3).

$$
\text { Fixed carbon yield }(\%)=Y(\%) \frac{(\% F C)}{100-\% a s h}
$$

The fixed carbon yield is proposed for assessing the conversion efficiency of the eucalyptus wood into fixed carbon. The fixed carbon yield approximates the percentage of pure carbon that can be obtained during the eucalyptus wood carbonization process. The fixed carbon yield has been widely accepted as an effective metric for evaluating the efficiency of the carbonization process and the quality of the produced charcoal as well.

\subsubsection{Charcoal Dispersion Preparation}

The carbonized charcoal was first crushed and grinded into fine particles. Then, the dispersion was prepared using the aqueous dispersion process. Initially, a quantity of water was poured in to a beaker along with the dispersant. Then, ethanol was added drop by drop to assist sonication and improve dispersion [8], and finally different concentrations of charcoal particles as shown in Table 5 as per the experimental design of response surface methodology by central composite design using Design expert 11 was designed. The mixture was stirred continuously using probe sonication for $15 \mathrm{~min}$, and then ultrasound bath sonication was used for $30 \mathrm{~min}$ to obtain homogenization of well-dispersed charcoal particles [24,25]. A cross-linking agent BTCA was added to improve the wash durability of the finish [26] and $\mathrm{MgCl}_{2}$ to catalyze the reaction of BTCA. The quality of the dispersion 
was controlled visually allowing the dispersion weeks as settling time $[6,25,27]$ in addition to the examination of the dispersion by the AATCC 146-2006, filter test method; dispersion evalauation procedure. When agglomerates of charcoal particles were observed, the dispersion was disqualified as insufficient and used no further. In case a homogeneous black dispersion observed, the dispersion was qualified as good as shown in Figure 1.

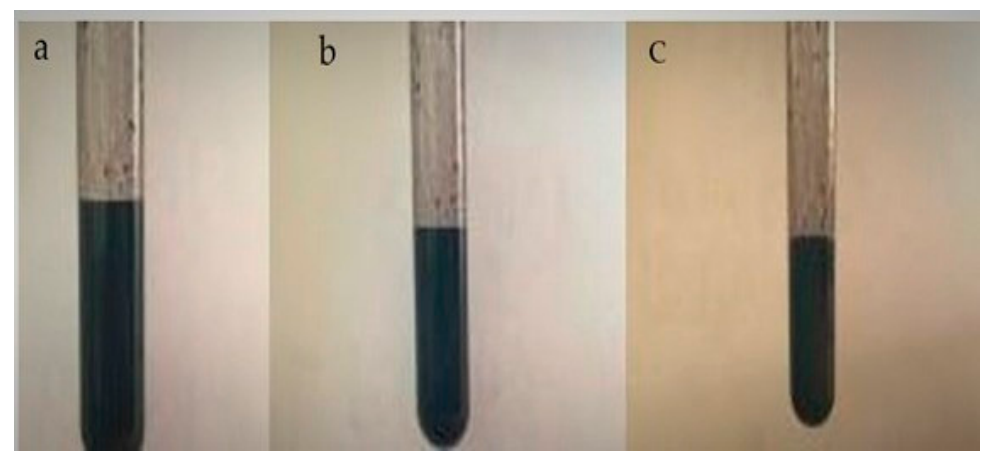

Figure 1. Photographs of the dispersion of the charcoal particles after (a) a week; (b) two weeks and (c) a month.

\subsubsection{Application of Charcoal Dispersion on to the Cotton Fabric}

After the charcoal dispersion preparation, it was applied on to fabric following AATCC test method 140-2006 by pad coating with a vertical padder lab 300 padding mangle that has a wet-pickup of $100 \%$. To increase charcoal loading, coating was done quadruple times. Thereafter, the fabric was dried at $105^{\circ} \mathrm{C}$ for $3 \mathrm{~min}$ and cured at $135^{\circ} \mathrm{C}$ for $5 \mathrm{~min}$ in a standard oven.

\subsection{Evaluation Parameters}

\subsubsection{Fourier Transform Infrared (FTIR) Analysis}

Infrared spectroscopy is ideal to confirm the presence of the charcoal particles in the coated samples. The surface features of charcoal and charcoal-coated fabric were examined by Perkin Elmer FTIR (FTIR-4000) (Waltham, MA, USA).

\subsubsection{Conductivity Measurement of Carbonized Charcoal}

The conductivity of charcoal was measured using the LCR meter, equipment used to measure inductance $(\mathrm{L})$, capacitance $(\mathrm{C})$ and resistance $(\mathrm{R})$. In this approach, two probes were mounted on a toolbar of bench top LCR meter, where one probe provides electrical current into the charcoal while the other probe receiving electrodes measuring the voltage drop between them. The data was measured at $136 \mathrm{~Hz}$ frequency. Thus, charcoal electrical conductivity was calculated and reported in terms of $\mathrm{Sm}^{-1}$.

\subsubsection{Conductivity Measurement of a Charcoal-Coated Fabric}

The conductivity of charcoal-coated cotton fabric was measured in terms of bulk resistance using a two-probe multimeter [28-30]. Two electrodes were placed on the surface of the sample, the distance between the electrodes was arranged to be $4 \mathrm{~cm} \times 4 \mathrm{~cm}$. The measurements were performed according to the AATCC test method 76-2005 standard test reference. The conductivity of the resulting fabric then calculated in $\mathrm{Scm}^{-1}$ using the following formulas as indicated in Equations (4)-(6).

$$
\begin{gathered}
R=R s=\rho \frac{L}{A} \\
\frac{R A}{L}=\rho
\end{gathered}
$$




$$
\sigma=\frac{1}{\rho}=\frac{L}{R A}=\frac{L}{R W t}
$$

where; $R=$ resistivity, $R_{\mathrm{s}}=$ bulk resistivity of fabric, $L=$ length of fabric, $\sigma=$ conductivity, $\rho=$ resistivity, $A=$ cross-sectional area of the fabric and $W$ and $t$ are width and thickness of the fabric.

\subsubsection{Assessment of Fastness Properties of Coated Fabric}

Washing fastness was tested according to the ISO 105 C06 2010 wash fastness standard test method [31] using auto launder-meter supplied by Mesdan Lab. AATCC test method 8-2007 was used to measure both dry and wet rubbing fastness employing the Mesdan lab crock meter and AATCC test method 162007 was used to measure the light-fastness by a solar-box. Perspiration fastness and fastness to hot pressing were also tested based on the AATCC test method 15-2009 test standard and AATCC test method 133-2009, respectively using perspirometer of type Electrical Heat Thermostatic Culture Box, Model DH-4000B supplied by Mesdan Lab for the former and hot-presser for the later.

\subsubsection{Durability Test to Washing}

The durability of electrical conductivity values against washing was examined following the AATCC test method 61-2006 by Autowash code 311f. The electrical conductivity of charcoal-coated cotton fabric was measured after each washing cycle.

\subsubsection{Evaluation of Sensorial Comfort Properties}

Kawabata Evaluation System (KES FB-AUTO A) was used to evaluate the sensorial comfort of fabrics, which includes shearing, compression, surface friction and roughness. Before testing, specimens of $20 \times 20 \mathrm{~cm}^{2}$ were conditioning for $24 \mathrm{~h}$. at $20{ }^{\circ} \mathrm{C}$ and $65 \%$ relative humidity (RH). Each trial was quintuple for each parameter in each sample and the average value was used for analysis. The surface roughness and surface friction were measured on KES-FBA of the surface tester. The compression and shear properties were measured using KES-FB3 and KES-FB1 compression and shear tester, respectively using the prescribed procedure by Kawabata and Niwa [32].

\subsubsection{Testing of Fabric Drape}

The fabric drape was measured based on BSISO1051 [33] using the Cusick drape tester. This test is used for the indication of the fabric appearance properties when fabric orients itself into folds in more than one plane under its own weight. The results obtained from this test method were used as an indication of the effects of coating on fabric stiffness.

\subsubsection{Testing of Tensile Strength}

The BS EN ISO 13934/1 tensile properties of textile fabrics standard test method was followed to test the tensile strength of the fabric by Tenso Lab 1000, Mesdan Lab [34] using the fabric strip traction method.

\subsubsection{Thermal Comfort}

The effect of charcoal loading on thermal properties such as thermal resistance, thermal conductivity and actual insulating of both controlled and coated samples was assessed as per the ASTM D5470 test method using a thermal interface tester (TIM Tester 1300A, Analysis Tech, Wakefield, MA, USA). Before testing, the specimens were conditioned for $24 \mathrm{~h}$. at $20^{\circ} \mathrm{C}$ and $65 \% \mathrm{RH}$. For the thermal behaviors, a contact area of $8.561 \mathrm{~cm}^{2}$ was used during testing.

\subsubsection{Water Permeability}

To determine the resistance of textiles to water penetration in liquid form, water resistance test was carried out by following the AATCC 22-2001 test method employing SDL spray rating tester (UK). 


\subsubsection{Air Permeability}

The breathability of charcoal-coated and controlled samples was evaluated in terms of air permeability. The test was performed as per BS EN ISO 9237:1995, determination of the air permeability of fabrics, by employing air permeability tester FX3300 (Schwerzenbach, Switzerland supplied by TexTest AG, Switzerland.

\section{Results and Discussion}

\subsection{Optimization of Carbonization Parameters of Eucalyptus Wood and Proximate Analysis of Charcoal}

All carbonized charcoals do not have the same chemical structure. The structure and hence the electrical and thermal properties of carbonized charcoal depends on the amount of temperature employed to carbonize the wood. Beyond a carbonization temperature of $800{ }^{\circ} \mathrm{C}$, wood charcoal possesses a graphite structure as claimed by Parfen'eva, L., et al., [35] and a carbon double bond and the aromatic ring are formed at a temperature of $600^{\circ} \mathrm{C}$ [36]. Upon carbonization, at a different time and temperature as shown in Table 1, for a prolonged time and temperature, the amount of fixed carbon yield and hence the conductivity increased. However, the yield of carbonization was reduced with increasing time and temperature. The increase in electrical conductivity is most likely due to the graphitization of wood charcoal so that each carbon atom in the charcoal will be covalently bonded to three others. There will be always a fourth atom, which is a free atom. This atom contains free delocalized electrons that can carry and pass on an electric charge. Besides, there is the formation of the synthetic graphite upon the removal of volatile matters due to structural rearrangement [37], the remaining mineral impurities also act as donors or acceptors and thereby drastically improving the electrical conductivity of the carbon charcoal $[35,38]$.

Table 1. Effects of time and temperature on fixed carbon content and conductivity.

\begin{tabular}{ccccc}
\hline Run & $\begin{array}{c}\text { Temperature (T) } \\
\left({ }^{\circ} \mathbf{C}\right)\end{array}$ & $\begin{array}{c}\text { Time (t) } \\
(\mathbf{m i n})\end{array}$ & $\begin{array}{c}\text { Fixed Carbon } \\
\text { Content } \mathbf{( F C )}(\mathbf{\%})\end{array}$ & $\begin{array}{c}\text { Conductivity }(\boldsymbol{\sigma}) \\
\left(\mathbf{S m}^{-\mathbf{1})}\right.\end{array}$ \\
\hline 1 & 596 & 45 & 78 & 396 \\
2 & 940 & 35 & 94 & 476 \\
3 & 700 & 30 & 81 & 455 \\
4 & 950 & 66 & 97 & 532 \\
5 & 950 & 40 & 93 & 473 \\
6 & 950 & 45 & 95 & 503 \\
7 & 940 & 40 & 94 & 481 \\
8 & 1200 & 60 & 98 & 540 \\
9 & 930 & 45 & 91 & 466 \\
10 & 950 & 23 & 89 & 453 \\
11 & 1303 & 45 & 96 & 523 \\
12 & 1200 & 30 & 90 & 460 \\
13 & 700 & 60 & 87 & 437 \\
\hline
\end{tabular}

As shown in the ANOVA model (Table 2), it was 95\% confident that there was a difference in fixed carbon yield between different runs based on Table 1 . Terms with a probability ( $p$-value) greater than 0.05 for constructed models are not significant. From the analysis of variance, the percentage of fixed carbon in terms of time and temperature is related in Equation (7).

$$
F C=14.15+0.12 T+0.26 t+0.000133 T t-0.000055 T^{2}-0.002000 t^{2}
$$

This equation used to make predictions about fixed carbon yield for the given temperature and time.

The adjusted coefficient of determination (adjusted $\mathrm{R}^{2}$ ) statistic value indicates that the model as fitted could explain 0.9381 of the variability in the fixed carbon content. This implies that $93.81 \%$ of 
the experiment values for fixed carbon content is reliable. Adequate precision measures the signal to noise ratio.

Table 2. ANOVA for the quadratic model of fixed carbon content.

\begin{tabular}{ccccccc}
\hline Source & $\begin{array}{c}\text { Sum of } \\
\text { Squares }\end{array}$ & $\mathbf{d f}$ & $\begin{array}{c}\text { Mean } \\
\text { Square }\end{array}$ & F-Value & $\boldsymbol{p}$-Value & Decision \\
\hline Model & 422.18 & 5 & 84.44 & 37.3500 & $<0.0001$ & significant \\
$\mathrm{T}$-Temperature & 258.28 & 1 & 258.28 & 114.2600 & $<0.0001$ & - \\
$\mathrm{t}$-Time & 80.10 & 1 & 80.10 & 35.4400 & 0.0006 & - \\
$\mathrm{Tt}$ & 1.00 & 1 & 1.00 & 0.4424 & 0.5273 & - \\
$\mathrm{T}^{2}$ & 82.80 & 1 & 82.80 & 36.6300 & 0.0005 & - \\
$\mathrm{t}^{2}$ & 1.41 & 1 & 1.41 & 0.6232 & 0.4558 & - \\
Residual & 15.82 & 7 & 2.26 & - & - & not significant \\
Lack of Fit & 6.62 & 3 & 2.21 & 0.9598 & 0.4930 & - \\
Pure Error & 9.20 & 4 & 2.30 & - & - & - \\
Cor Total & 438.00 & 12 & - & - & & - \\
\hline
\end{tabular}

A ratio greater than 4 is desirable, where a ratio of 19.9547 indicates an adequate signal. The fixed carbon yield increases with increasing time and temperature as shown in Figure 2a. The conductivity of the charcoal with determinant variables indicates that as the temperature and time increases, conductivity rises as shown in Figure $2 b$, which affirms conductivity is directly related to fixed carbon content.

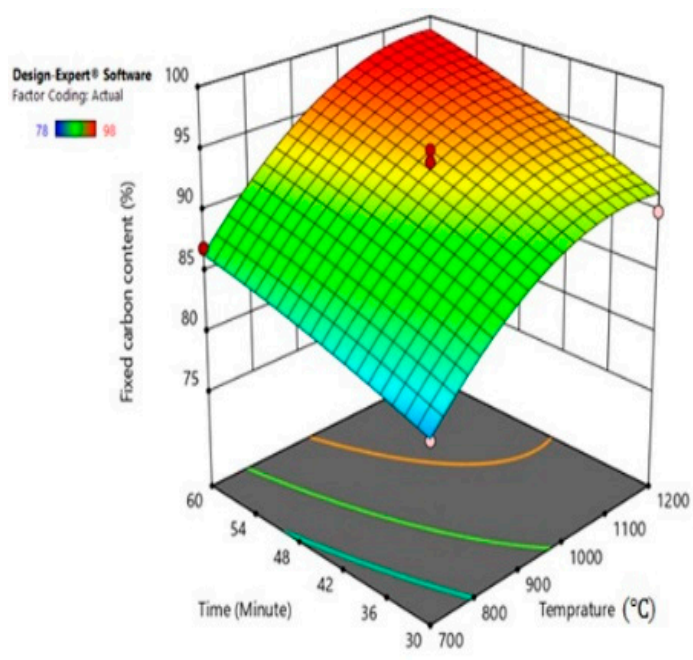

a

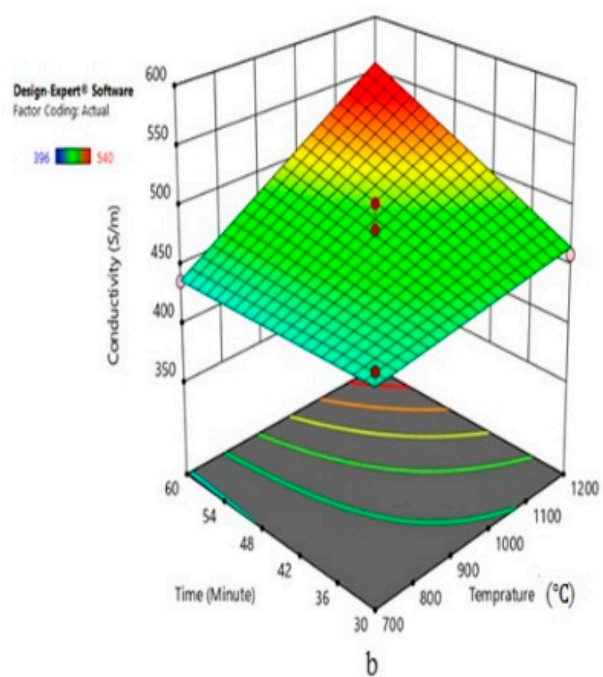

Figure 2. 3-D graph of relations of time and temperature with fixed carbon content (a) and conductivity (b).

As shown in Table 3, the conductivity of carbonized charcoal has a difference among the different runs with a $95 \%$ confidence level. The relationship between conductivity with carbonized time and temperature is explained in Equation (8).

$$
\sigma\left(\mathrm{Sm}^{-1}\right)=554.08-0.15 \mathrm{~T}-4.75 \mathrm{t}+0.007 \mathrm{Tt}
$$

The fit statistics for the model of conductivity specify $79.88 \%$ adjusted $\mathrm{R}^{2}$. The adequate precision ratio was 13.28 implying that the model had a high signal-to-noise ratio, which qualified it to navigate the design space. The relationship between conductivity with carbonized time and temperature is shown in Figure $2 \mathrm{~b}$. The optimum value of the fixed carbon content with the desirability of 0.585 was $91.156 \%$ carbonizing the wood at a temperature of $928^{\circ} \mathrm{C}$ and $37 \mathrm{~min}$; this gives an electrical conductivity of $463.34 \mathrm{Sm}^{-1}$ of charcoal compared to the immeasurable conductivity of wood. 
Table 3. ANOVA for the two-factor interaction model of conductivity.

\begin{tabular}{ccccccc}
\hline Source & $\begin{array}{c}\text { Sum of } \\
\text { Squares }\end{array}$ & df & $\begin{array}{c}\text { Mean } \\
\text { Square }\end{array}$ & F-Value & $\boldsymbol{p}$-Value & Decision \\
\hline Model & $16,513.04$ & 3 & 5504.35 & 16.8800 & 0.0005 & significant \\
T-Temperature & $10,339.59$ & 1 & $10,339.59$ & 31.7100 & 0.0003 & - \\
t-Time & 3772.45 & 1 & 3772.45 & 11.5700 & 0.0079 & - \\
Tt & 2401.00 & 1 & 2401.00 & 7.3600 & 0.0238 & - \\
Residual & 2934.19 & 9 & 326.02 & - & - & - \\
Lack of Fit & 2143.39 & 5 & 428.68 & 2.1700 & 0.2366 & not significant \\
Pure Error & 790.80 & 4 & 197.70 & - & - & - \\
Cor Total & $19,447.23$ & 12 & - & - & - & - \\
\hline
\end{tabular}

The carbonization yield obtained at a temperature of $928{ }^{\circ} \mathrm{C}$ and time of $37 \mathrm{~min}$ was $64.7 \%$, whereas the fixed carbon yield was $59.17 \%$. The properties of charcoal used for coating of cotton fabrics are shown in Table 4.

Table 4. Proximate analysis of charcoal.

\begin{tabular}{cc}
\hline Parameters & Values (\%) \\
\hline Moisture & 3.5 \\
Volatile matter & 5.0 \\
Ash & 0.5 \\
Fixed carbon & 91.0 \\
content & 64.7 \\
Yield & 59.17 \\
FC yield & \\
\hline
\end{tabular}

\subsection{Coating Formulation and Improved Electrical Conductivity of Charcoal-Coated Fabrics.}

The cotton fabric was easily pad-coated by a solution based on charcoal. After pad coating, the charcoal coated textiles became black as shown in Figure 3.

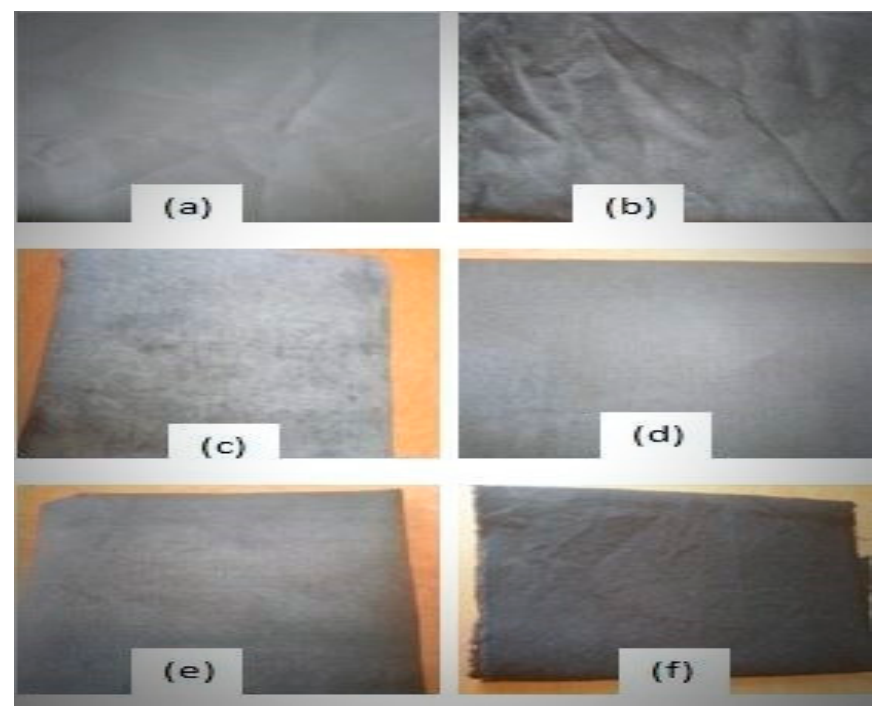

Figure 3. Controlled sample (a) and coated samples using coating mixtures of $7 \mathrm{mg} / \mathrm{mL}$ dispersant, $4 \mathrm{mg} / \mathrm{mL}$ ethanol, $6 \mathrm{mg} / \mathrm{mL}$ BTCA, $4 \mathrm{mg} / \mathrm{ml}$ of $\mathrm{MgCl}_{2}$, plus $4 \mathrm{mg} / \mathrm{mL}$; (b) $6 \mathrm{mg} / \mathrm{mL}$; (c) $7.5 \mathrm{mg} / \mathrm{mL}$; (d) $9 \mathrm{mg} / \mathrm{mL}$; (e) $10 \mathrm{mg} / \mathrm{mL}$ and (f) charcoal particles. 
The coated textile shows a drastic increase in the electrical conductivity as shown in Table 5. This is due to the formation of a conductive pathway on textiles caused by the adherent of charcoal particles on to textiles.

Table 5. Coating mixtures and improved conductivity of the fabric.

\begin{tabular}{ccccc}
\hline Run & $\begin{array}{c}\text { A: Charcoal Particles } \\
\mathbf{m g} / \mathbf{m L}\end{array}$ & $\begin{array}{c}\text { B: Dispersant } \\
\mathbf{m g} / \mathbf{m L}\end{array}$ & $\begin{array}{c}\text { C: Ethanol } \\
\mathbf{m g} / \mathbf{m L}\end{array}$ & $\begin{array}{c}\text { Conductivity } \\
\mathbf{S c m}^{\mathbf{- 1}}\end{array}$ \\
\hline 1 & 7.5 & 8.5 & 2.5 & 108 \\
2 & 6.0 & 10.0 & 4.0 & 109 \\
3 & 6.0 & 7.0 & 1.0 & 81 \\
4 & 7.5 & 8.5 & 2.0 & 106 \\
5 & 7.5 & 8.0 & 2.5 & 89 \\
6 & 9.0 & 7.0 & 4.0 & 126 \\
7 & 6.0 & 7.0 & 4.0 & 98 \\
8 & 8.0 & 8.5 & 2.5 & 119 \\
9 & 7.5 & 8.5 & 5.0 & 112 \\
10 & 9.0 & 10.0 & 1.0 & 103 \\
11 & 4.97 & 8.5 & 2.5 & 79 \\
12 & 7.5 & 5.9 & 2.5 & 101 \\
13 & 10.2 & 2.5 & 1.5 & 148 \\
14 & 6.0 & 10.0 & 1.0 & 96 \\
15 & 9.0 & 10.0 & 4.0 & 121 \\
16 & 7.5 & 7.5 & 2.5 & 73 \\
17 & 7.5 & 8.5 & 0.0 & 86 \\
18 & 7.5 & 11.0 & 2.5 & 91 \\
19 & 7.5 & 8.0 & 2.0 & 87 \\
20 & 9.0 & 7.0 & 1.0 & \\
\hline
\end{tabular}

There was a significant difference in the conductivity of coated fabrics among different coating mixtures with a $95 \%$ confidence level as shown in Table 6 . Though the conductivity increased with increasing charcoal particles as shown in Figure 4, the optimum value of coating mixtures with a desirability of 0.882 selected among 52 solutions were $9 \mathrm{mg} / \mathrm{mL}$ charcoal particles, $7 \mathrm{mg} / \mathrm{mL}$ dispersant and $4 \mathrm{mg} / \mathrm{mL}$ ethanol plus $6 \mathrm{mg} / \mathrm{mL}$ BTCA and $4 \mathrm{mg} / \mathrm{mL} \mathrm{MgCl}$. Applying the selected mixture in the sample gives the conductivity of $124.49 \mathrm{~S} / \mathrm{cm}^{-1}$. A fabric with this optimized mixture was used in all fabric testing and proof of concept development.

Table 6. ANOVA for the linear model of conductivity.

\begin{tabular}{ccccccc}
\hline Source & $\begin{array}{c}\text { Sum of } \\
\text { Squares }\end{array}$ & df & $\begin{array}{c}\text { Mean } \\
\text { Square }\end{array}$ & F-Value & $p$-Value & Decision \\
\hline Model & 3804.06 & 3 & 1268.02 & 8.5400 & 0.0013 & significant \\
Charcoal particles & 2092.41 & 1 & 2092.41 & 14.1000 & 0.0017 & - \\
Dispersant & 10.15 & 1 & 10.15 & 0.0684 & 0.7971 & not significant \\
Ethanol & 1701.50 & 1 & 1701.50 & 11.4600 & 0.0038 & - \\
Residual & 2375.14 & 16 & 148.45 & - & - & - \\
Lack of Fit & 1745.81 & 11 & 158.71 & 1.2600 & 0.4236 & not significant \\
Pure Error & 629.33 & 5 & 125.87 & - & - & - \\
Cor Total & 6179.20 & 19 & - & - & - & - \\
\hline
\end{tabular}




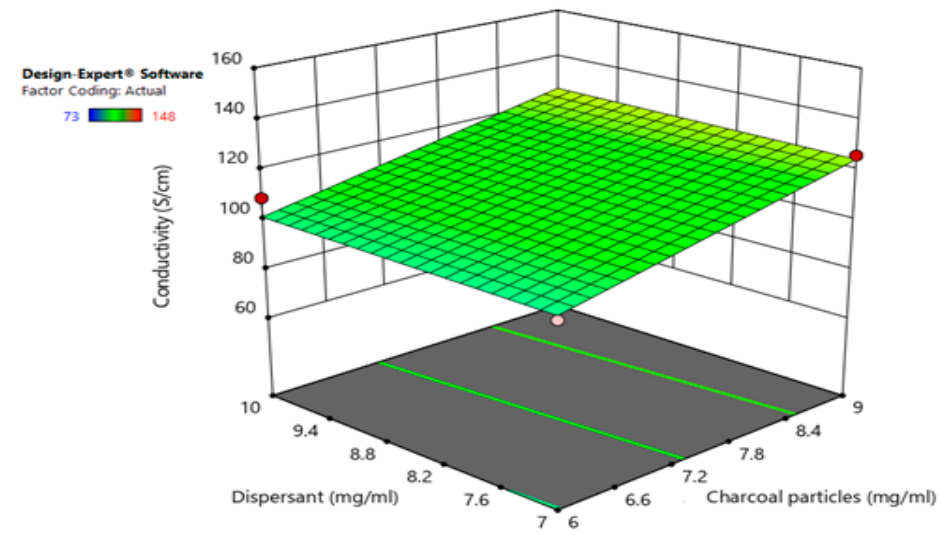

(a)

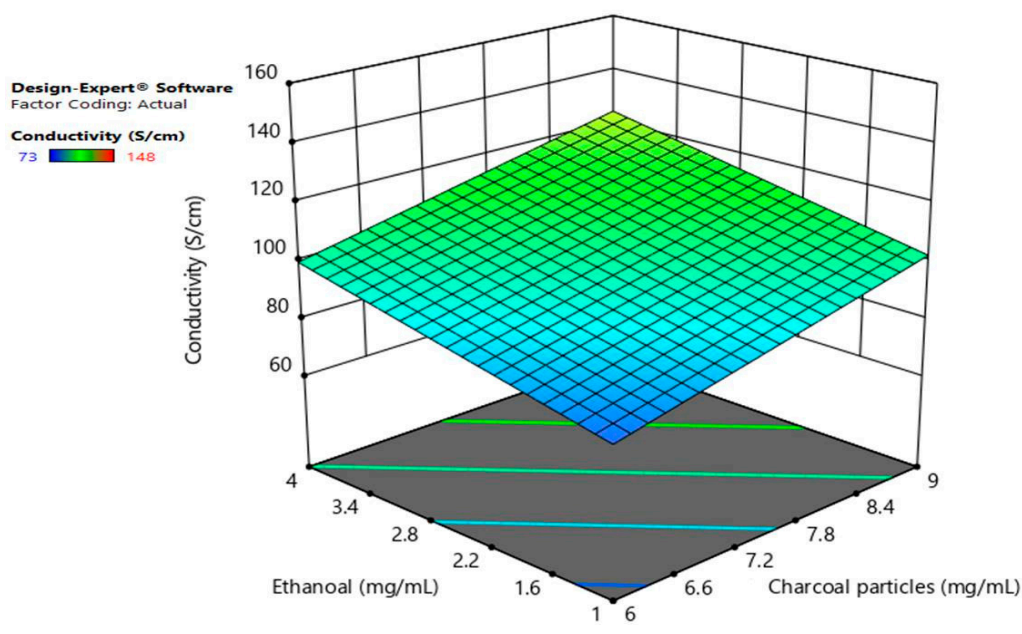

(b)

Figure 4. 3D graphical relation of $\sigma$ with dispersant (a) andethanol (b) versus charcoal particles.

\subsection{Analysis of Charcoal and Wood Using FTIR}

The FTIR spectra of the original eucalyptus wood and charcoal carbonized at $928^{\circ} \mathrm{C}$ for $37 \mathrm{~min}$ are illustrated in Figure 5. Initially, the intensity of the band around $3111.8 \mathrm{~cm}^{-1}$ due to the vibrational mode of $\mathrm{OH}$ stretching bond in the wood was relatively higher than in the charcoal, which suggests a loss of the constitution water that is impregnated in the cell wall of wood and the decomposition $\mathrm{OH}$ group of cellulose by an increase in temperature.

The decomposition of lignin is evidenced by the reduction of $\mathrm{C}=\mathrm{C}$ vibrational bands of aromatic rings at in $1153 \mathrm{~cm}^{-1}$. The nonconjugated bonds $\mathrm{C}=\mathrm{O}$ in $1725 \mathrm{~cm}^{-1}$ assigned to hemicelluloses decreased markedly in intensity. A formation of an aromatic network with the appearance of three bands at low frequencies 881,823 and $772 \mathrm{~cm}^{-1}$, from the angular deformation outside the plane of the ring $\mathrm{CH}$ groups. Nishimiya, K., et al. [37] claimed that the aromatic mode due to lignin was changed to a different type of aromatic compound by the carbonization process. The peaks in the FTIR curve in Figure 5 showed that there was a change in the chemical composition of the cotton textile after being pad-coated with the charcoal dispersion depicting that the charcoal was attached to the fabric. This is recognized by the introduction of the aromatic groups in the cotton fabric. The cotton fabric introduces an aromatic $\mathrm{C}=\mathrm{C}$ conjugated group at $1500 \mathrm{~cm}^{-1}$ after coated using charcoal, which conforms the adhesion of charcoal loading on the cotton fabric. 


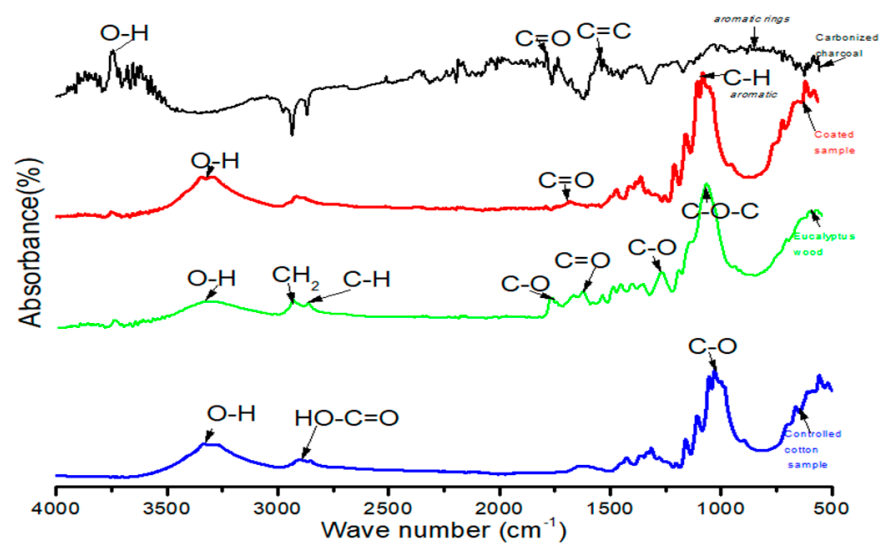

Figure 5. Infrared spectra of eucalyptus wood, charcoal, charcoal coted and controlled samples.

The intensity of band around $3335 \mathrm{~cm}^{-1}$ in cellulose due to $\mathrm{OH}$ vibration was higher than the controlled sample where there was $\mathrm{C}=\mathrm{C}-\mathrm{H}$ at this wavenumber in the coated sample. Below $1000 \mathrm{~cm}^{-1}$, the aromatic absorption of coated sample was higher. This all signifies that charcoal dispersion was properly adhered on to the surface of the cotton substrate.

\subsection{Coating Fastness Properties and Wash Durability}

Conductive textiles should not only have the desired electrical conductivity properties, but also acceptable quality characteristics as explained by Smith, W.C. [39] Smith also suggests determining different coating fastness properties using their respective textile standards as performed in this paper, or modified versions.

Coating fastness to washing and perspiration of the charcoal coated fabric was evaluated. It was assessed in respect to color change and staining on cotton and polyester as shown in Table 7. It can be seen that charcoal coated fabric had a color change by a half grade lower than the original both in the wash and perspiration fastness with no staining to the polyester fabric.

Table 7. Effect of different fastening agents on coated fabrics.

\begin{tabular}{|c|c|c|c|c|c|c|}
\hline \multirow{2}{*}{ Fastness Properties } & \multirow{2}{*}{\multicolumn{2}{|c|}{ Color Change }} & \multicolumn{4}{|c|}{ Staining } \\
\hline & & & \multicolumn{2}{|c|}{ Cotton } & \multicolumn{2}{|c|}{ Polyester } \\
\hline Wash fastness (ISO 105 C06 2010) & \multicolumn{2}{|c|}{$4 / 5$} & \multicolumn{2}{|c|}{$4 / 5$} & \multicolumn{2}{|c|}{5} \\
\hline Light fastness (AATCC Test Method 16 2007) & \multicolumn{2}{|c|}{7} & \multicolumn{2}{|c|}{ - } & \multicolumn{2}{|c|}{ - } \\
\hline Perspiration fastness (AATCC Test Method 15-2009) & $\begin{array}{l}\text { Alkaline } \\
4 / 5\end{array}$ & $\begin{array}{l}\text { Acidic } \\
4 / 5\end{array}$ & $\begin{array}{c}\text { Alkaline } \\
4 / 5\end{array}$ & $\begin{array}{c}\text { Acidic } \\
4 / 5\end{array}$ & $\begin{array}{l}\text { Alkaline } \\
4 / 5\end{array}$ & $\begin{array}{l}\text { Acidic } \\
5\end{array}$ \\
\hline Hot pressing (AATCC Test Method 133-2009) & $\begin{array}{c}\text { Dry } \\
5\end{array}$ & $\begin{array}{l}\text { wet } \\
4 / 5\end{array}$ & $\begin{array}{c}\text { Dry } \\
5\end{array}$ & $\begin{array}{l}\text { Wet } \\
4 / 5\end{array}$ & $\begin{array}{c}\text { Dry } \\
5\end{array}$ & $\begin{array}{l}\text { Wet } \\
4 / 5\end{array}$ \\
\hline Rubbing fastness (AATCC Test Method 8-2007) & \multicolumn{2}{|c|}{-} & \multicolumn{2}{|c|}{$\begin{array}{c}\text { Dry } \\
5\end{array}$} & \multicolumn{2}{|c|}{$\begin{array}{l}\text { Wet } \\
4 / 5\end{array}$} \\
\hline
\end{tabular}

Though cotton textile remained black just as it was coated after normal washing, it was observed that when it was laundered repeatedly, the charcoal particles were removed from the textile and precipitated in the water. As a result, the bare parts of the cotton fiber increased and conductivity of cotton fabric decreased as shown in Figure 6. 


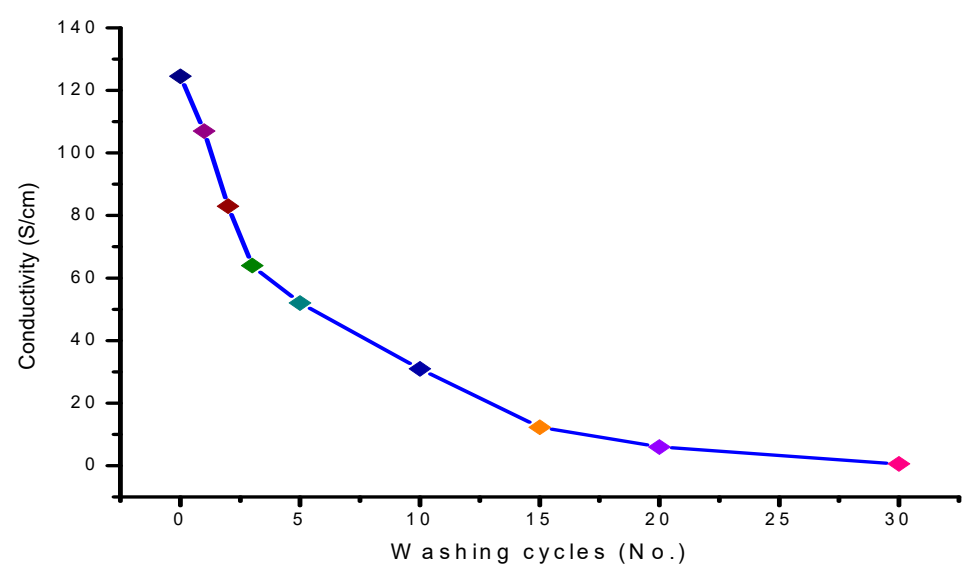

Figure 6. Wash durability of conductivity of charcoal-coated fabrics.

This may be due to the disruption of the formed conductive paths formed by charcoal particles earlier. In the case of rub fastness, dry rub fastness of the coated fabric was outstanding with no change; whereas wet rub fastness was a half grade lower than its initial as shown in Table 7, the light-fastness and hot pressing were still reasonable due to the fact that the adherence of charcoal particles on to the cotton fabric was enhanced by BTCA cross-linkers [26] and electrostatic adhesion of charcoal particles on the surface of cotton fabric. In addition, the deposition of the charcoal particles on the amorphous and pores part of the cotton textile assisted in obtaining high coating fastness properties.

\subsection{Effect of Coating on Tensile Strength and Drapability of Fabric}

The mean tensile strength of the charcoal-coated cotton fabric was found to be $294 \mathrm{~N}$, which is higher than the corresponding controlled sample of $269 \mathrm{~N}$ at a mean elongation of $10.5 \%$ and $6 \%$, respectively in the warp direction. The mean tensile strength of the filling was 245 and $271 \mathrm{~N}$ with a mean elongation of $17 \%$ and $15.9 \%$ for controlled and coated samples, respectively as shown in Figure 7. The heat treatment during drying and curing of fabric may be the probable reason for the coated sample to stretch more easily. However, the effect of coating on mechanical properties will be discussed in the future scope.

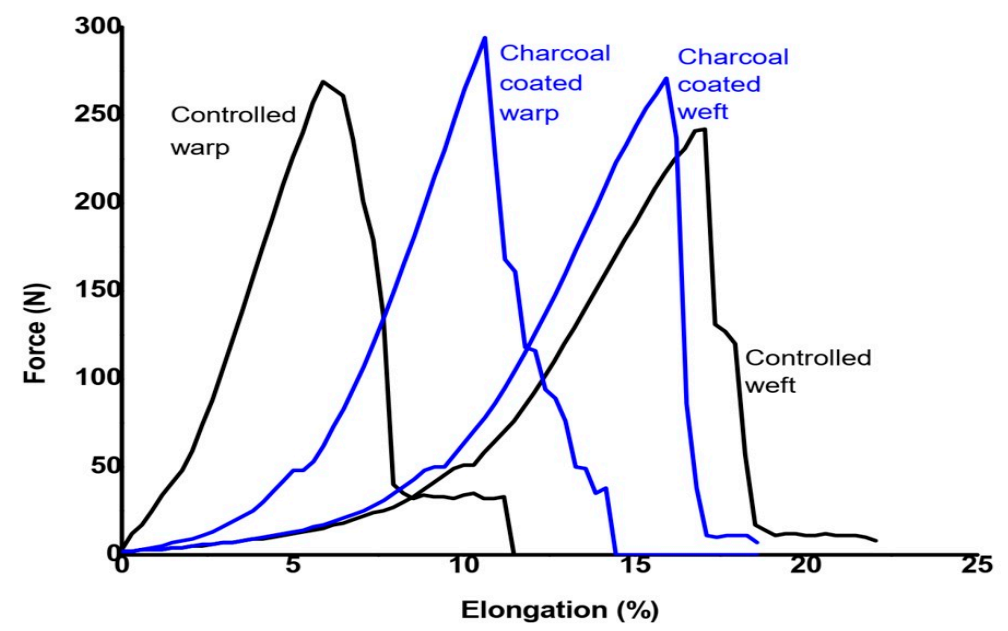

Figure 7. Mean tensile strength and breaking elongation of controlled and charcoal coated samples.

The drape coefficient of charcoal-coated cotton fabric was $84.23 \%$, which was stiffer than the controlled sample having a drape coefficient of $81.92 \%$, although both samples were neither rigid nor limp. This is mostly due to the stiffening effect of the charcoal coating as a result of an increase in compactness because of charcoal loading. 


\subsection{Evaluation of Comfort Properties}

With $95 \%$ confident, the tactile and thermal properties of charcoal-coated and controlled samples had significant differences except for the roughness as shown in Table 8. The coefficient of friction was inversely related to slipperiness. The controlled sample was more slippery than charcoal coated cotton fabric. MMD was correlated with the smoothness and roughness felt when the surface of an object was rubbed, and a larger MMD value indicates a rougher surface. The $t$-test shows there was no difference in roughness in the weft direction.

Table 8. Effect of coating on comfort properties.

\begin{tabular}{|c|c|c|c|c|c|c|c|}
\hline \multicolumn{3}{|c|}{ Mechanical Properties } & Mean & $\begin{array}{l}\text { Standard } \\
\text { Error }\end{array}$ & $\begin{array}{c}\mathrm{T} \\
\text { Statistics }\end{array}$ & $\begin{array}{c} \pm t \\
\text { Critical }\end{array}$ & $\begin{array}{c}\text { Decision } p(\mathrm{~T}<=\mathrm{t}) \\
\text { Two-Tail } \alpha=0.5\end{array}$ \\
\hline \multicolumn{8}{|c|}{ Surface roughness and friction properties } \\
\hline \multirow{3}{*}{ MIU } & Weft & $\begin{array}{c}\text { Controlled } \\
\text { Coated }\end{array}$ & $\begin{array}{l}0.1288 \\
0.1514\end{array}$ & $\begin{array}{l}0.0028 \\
0.0054\end{array}$ & -2.9137 & & 0.0435 \\
\hline & \multirow{2}{*}{ Warp } & Controlled & 0.1634 & 0.0034 & \multirow{2}{*}{-13.4007} & & \multirow{2}{*}{0.0001} \\
\hline & & Coated & 0.4116 & 0.0178 & & & \\
\hline \multirow{3}{*}{ MMD } & \multirow{2}{*}{ Weft } & Controlled & 0.0128 & 0.0002 & \multirow{2}{*}{-1.9367} & & \multirow{2}{*}{0.1248} \\
\hline & & Coated & 0.0143 & 0.0006 & & 2.7764 & \\
\hline & Warp & $\begin{array}{c}\text { Controlled } \\
\text { Coated }\end{array}$ & $\begin{array}{l}0.0163 \\
0.0411\end{array}$ & $\begin{array}{l}0.0003 \\
0.0017\end{array}$ & -13.4008 & & 0.0001 \\
\hline \multirow{4}{*}{ SMD } & \multirow{2}{*}{ Weft } & Controlled & 1.2832 & 0.0268 & \multirow{2}{*}{-2.2939} & & \multirow{2}{*}{0.0834} \\
\hline & & Coated & 1.6180 & 0.1437 & & & \\
\hline & \multirow{2}{*}{ Warp } & Controlled & 1.6320 & 0.0335 & \multirow{2}{*}{-13.4727} & & \multirow{2}{*}{0.00017} \\
\hline & & Coated & 4.1660 & 0.1783 & & & \\
\hline \multicolumn{8}{|c|}{ Shear Properties } \\
\hline \multirow{4}{*}{ G, go/cm.deg } & \multirow{2}{*}{ Weft } & Controlled & 1.7220 & 0.0058 & \multirow{2}{*}{-9.2184} & & \multirow{2}{*}{0.0007} \\
\hline & & Coated & 2.3620 & 0.0688 & & & \\
\hline & Warp & Controlled & 1.7780 & 0.0159 & & & 00001 \\
\hline & warp & Coated & 2.4880 & 0.0476 & -13.1844 & & 0.0001 \\
\hline & & Controlled & 3.4680 & 0.0511 & & & \\
\hline $2 \mathrm{HG}, \mathrm{gf} / \mathrm{cm}$ & Weft & Coated & 4.0980 & 0.0662 & -17.4063 & 27764 & 0.0000 \\
\hline $21 \mathrm{G}, \mathrm{g} / \mathrm{Cllt}$ & Warn & Controlled & 3.5380 & 0.0897 & -39131 & 2.1764 & 00173 \\
\hline & svaip & Coated & 4.4080 & 0.1658 & -3.9131 & & $0.01 / 3$ \\
\hline & & Controlled & 5.7940 & 0.1053 & & & \\
\hline $5 \mathrm{HG}$ of $/ \mathrm{cm}$ & Weft & Coated & 6.5100 & 0.13453 & -14.8459 & & 0.0001 \\
\hline bHG, gt/cm & Warn & Controlled & 6.5400 & 0.1126 & & & \\
\hline & Warp & Coated & 7.5520 & 0.1096 & -13.6907 & & 0.0001 \\
\hline & & & Compress & Properties & & & \\
\hline $\mathrm{I} C(-)$ & & olled & 0.4372 & 0.0016 & 46761 & & م0094 \\
\hline $\mathrm{LC}(-)$ & & & 0.4826 & 0.0082 & $4.6 / 61$ & & 0.0094 \\
\hline WC & & olled & 0.1894 & 0.0015 & & & ( \\
\hline (gf.cm/ $\left./ \mathrm{cm}^{2}\right)$ & & ted & 0.1798 & 0.0021 & -3.3005 & 2.7764 & 0.0299 \\
\hline RC (\%) & & olled & 36.372 & 0.2813 & & & 00015 \\
\hline $\mathrm{KC}(\%)$ & & & 34.098 & 0.0315 & 7.6969 & & 0.0015 \\
\hline $\mathrm{T}(\mathrm{mm})$ & & olled & 0.5212 & 0.0047 & -209027 & & 0.0000 \\
\hline 1 (IIII) & & ted & 0.6350 & 0.0022 & -20.9027 & & \\
\hline
\end{tabular}

where MIU = Coefficient of friction, MMD = Mean deviation of MIU, SMD = Geometrical roughness, G = Shear rigidity, $2 \mathrm{G}=$ Hysteresis of shear force at $0.5^{\circ}, 5 \mathrm{G}=$ Hysteresis of shear force at $5^{\circ}, \mathrm{LC}=$ Linearity of compression, $\mathrm{WC}=$ Compressional energy, $\mathrm{RC}=$ Compressional resilience.

SMD, geometrical roughness, which is a measure of surface topography, indicates the surface physical evenness, and a higher value shows an uneven surface. The charcoal coating creates a bumpy surface on the cotton fabric. These observations were in the warp direction.

The shear rigidity of the charcoal-coated fabric was higher than the controlled sample. This may be due to the higher coefficient of friction and flexural rigidity of the coated sample due to the effect of charcoal loading on increasing compactness of the fabric. The $2 \mathrm{G}$ and $5 \mathrm{G}$ hysteresis of shear 
force at $0.5^{\circ}$ and $5^{\circ}$, respectively, were higher for charcoal coated cotton textiles than the uncoated controlled sample.

As a result of a compact structure of the coated sample, once the yarns were sheared, it was difficult to recover to its original position in both the warp and weft direction. The linear compressibility of fabric, which is a reduction in thickness with the application of $50 \mathrm{gf} / \mathrm{cm}^{2}$ pressure was difficult for coated fabric and hence the lower compressional energy was obtained in coated fabric $[40,41]$. The controlled sample had better retention after compression. This was likely because of the increase in the thickness of the fabric after coating, and the effect of coating on bending stiffness.

\subsection{Effect of Coating on Thermal Conductivity}

Thermal conductivity is the transmission of molecular vibrations through a material measured as temperature change. Generally, the more rigid the material the faster the transmission and the higher the amount of heat transmitted. Since the intermolecular spacing in the charcoal coated fabric is larger than the controlled sample, the motion of molecules in the charcoal coated fabric will be more regular than the corresponding controlled sample thereby thermal conductivity will be higher and will be ineffective in thermal resistance and actual insulation as shown in Table 9. Besides, entrapped air, which acts as a barrier for thermal conductivity is reduced in coated fabrics [42].

Table 9. Effect of coating on thermal conductivity and air permeability.

\begin{tabular}{|c|c|c|c|c|c|c|}
\hline \multicolumn{2}{|c|}{ Comfort Properties } & Mean & $\begin{array}{l}\text { Standard } \\
\text { Error }\end{array}$ & T Statistics & $\begin{array}{c} \pm \mathrm{t} \\
\text { Critical }\end{array}$ & $\begin{array}{c}\text { Decision } p(\mathrm{~T}<=\mathrm{t}) \\
\quad \text { Two-Tail } \alpha=0.5\end{array}$ \\
\hline \multicolumn{7}{|c|}{ Thermal Properties } \\
\hline Conductivity (w/mk) & $\begin{array}{l}\text { Controlled } \\
\text { Coated }\end{array}$ & $\begin{array}{l}0.045 \\
0.079\end{array}$ & $\begin{array}{l}0.0012 \\
0.0013\end{array}$ & -22.4189 & \multirow{3}{*}{2.7764} & 0.0000 \\
\hline Resistance (inch $\left.{ }^{2} . \mathrm{k} / \mathrm{w}\right)$ & $\begin{array}{l}\text { Controlled } \\
\text { Coated }\end{array}$ & $\begin{array}{l}2.151 \\
1.790\end{array}$ & $\begin{array}{l}0.0099 \\
0.0007\end{array}$ & 34.5621 & & 0.0000 \\
\hline Insulation $(\mathrm{k} / \mathrm{w})$ & $\begin{array}{l}\text { Controlled } \\
\text { Coated }\end{array}$ & $\begin{array}{c}2.0718 \\
1.764\end{array}$ & $\begin{array}{l}0.0384 \\
0.0222\end{array}$ & 6.7553 & & 0.0025 \\
\hline \multicolumn{7}{|c|}{ Air Permeability } \\
\hline $\begin{array}{c}\text { Air } \\
\text { permeability }\left(\mathrm{cm}^{3} / \mathrm{cm}^{2} / \mathrm{s}\right)\end{array}$ & $\begin{array}{l}\text { Controlled } \\
\text { Coated }\end{array}$ & $\begin{array}{l}49.380 \\
48.040\end{array}$ & $\begin{array}{l}0.5285 \\
0.7560\end{array}$ & -3.9757 & 2.7764 & 0.0164 \\
\hline
\end{tabular}

\subsection{Effect of Coating on Air Permeability}

The air permeability of controlled fabric sample was $49.38 \pm 0.528583 \mathrm{~cm}^{3} / \mathrm{cm}^{2} / \mathrm{s}$ at 100 Pascal air pressures, which decreased to $48.04 \pm 0.7560423 \mathrm{~cm}^{3} / \mathrm{cm}^{2} / \mathrm{s}$ for the charcoal coated cotton fabric. The decrease in air permeability was due to the fact that the coating material to some extent blocked the interstices and pores in the fabric.

\subsection{Water Permeability}

The spray rating of the charcoal-coated cotton fabric in the chart card rating was 70 , which means partial wetting of the whole upper surface. However, the controlled fabric sample was completely wet on the whole upper surface with the chart card rating of 50. This was most likely due to the hydrophobic nature of charcoal forming low energy surfaces on the cotton fabric [43].

\section{Proof of Concept}

For corroboration conductivity, a light-emitting diode was lit up by powering a charcoal coated cotton textile with a DC power supply verifying that charcoal coated cotton fabric was electrically conductive, as shown in Figure 8. 


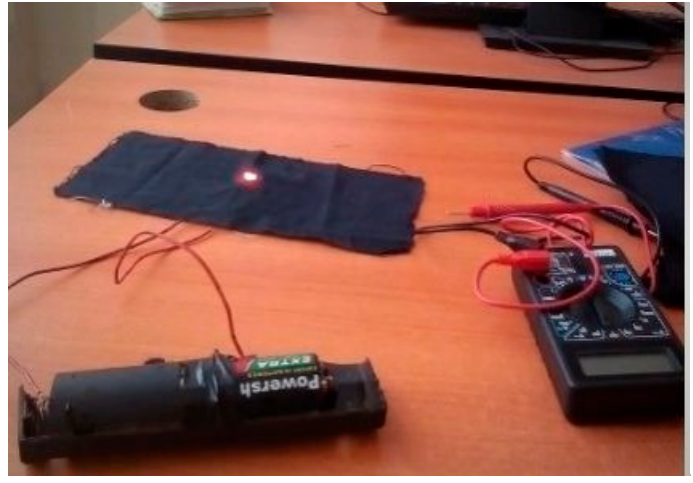

(a)

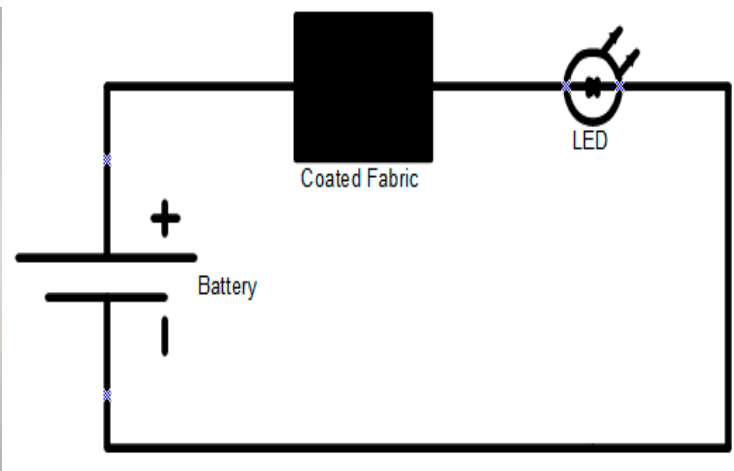

(b)

Figure 8. A conductive cotton fabric lights up by light-emitting diode connected with DC power (a) and its circuit scheme $(\mathbf{b})$.

This proof of concept and all the above results regarding electrical conductivity and other fabric properties shows a promising potential to use the resulting fabric as electromagnetic shielding [44], mechanical sensors and actuators [45,46], flexible heating elements [47] and for functions that often require a fabric with electro-activity.

\section{Conclusions}

This paper presented routes to achieving electrically conductive textile by coating the fabric with a dispersion based on charcoal. Immeasurable conductivity of eucalyptus wood changes form to become electrically conductive through carbonization at high temperature and time. A stable dispersion was prepared from charcoal particles by reducing the particle size and producing homogenization through probe sonication and ultrasound sonication, respectively. An elevated conductivity of $124.49 \mathrm{Scm}^{-1}$ was developed by pad coating of a higher resistive cotton fabric through a dispersion based on charcoal. Reasonable fastness properties of the coating were obtained when the coated sample assessed different fastness agents in a way that is done in textile industries. This is most likely due to the electrostatic attraction between the cotton substrate and charcoal particles besides the crosslinking effect of BTCA. However, under repeated laundering, the conductivity of charcoal coated fabric was affected. Tactile properties such as shear and compression were affected. In addition, the breathability of fabrics such as air permeability and water permeability was affected by the coating.

The durability to washing is a limitation of the current technique. To overcome this effect, dry cleaning should be attempted for future studies. The technology is expected to have commercial potential as it has a high possibility to be integrated into the existing wet processing methods.

Author Contributions: Conceptualization, E.K. and A.H.; Methodology, E.K and A.H.; Validation, E.K. and A.H.; Formal Analysis, E.K., A.H. and M.G.; Investigation, E.K.; Resources, E.K., A.H. and M.G.; Writing-Original draft preparation, E.K.; Writing-Review and editing, E.K. and M.G.; Visualization, E.K.; Supervision, A.H.; Project Administration, A.H.; Funding Acquisition, A.H. and M.G. All authors contributed equally to the work reported. All authors have read and agreed to the published version of the manuscript.

Funding: This work was funded by Ethiopian Institute of Textile and Fashion Technology, Bahir Dar University, Ethiopia.

Conflicts of Interest: The authors declare no conflict of interest.

\section{References}

1. Stoppa, M.; Chiolerio, A. Wearable electronics and smart textiles: A critical review. Sensors. 2014, 14, 11957-11992. [CrossRef] [PubMed]

2. Hu, X.; Tian, M.; Qu, L.; Zhu, S.; Han, G. Multifunctional cotton fabrics with graphene/polyurethane coatings with far-infrared emission, electrical conductivity, and ultraviolet-blocking properties. Carbon 2015, 95, 625-633. [CrossRef] 
3. Goto, H.; Tomioka, H.; Gunji, T.; Nagao, Y.; Misono, T.; Abe, Y. Preparation of continuous ZrO2-Y2O3 fibers by precursor method using polyzirconoxane. J. Ceram. Soc. Jpn. 1993, 101, 336-341. [CrossRef]

4. Meoli, D.; May-Plumlee, T. Interactive electronic textile development: A review of technologies. J. Text. Apparel. Technol. Manag. 2002, 2, 1-12.

5. Islam, R.; Khair, N.; Ahmed, D.; Shahariar, H. Fabrication of low cost and scalable carbon-based conductive ink for E-textile applications. Mater. Today. Commun. 2019, 19, 32-38. [CrossRef]

6. Rahman, J.M.; Mieno, T. Conductive cotton textile from safely functionalized carbon nanotubes. J. Nanomater. 2015, 16, 187. [CrossRef]

7. Zhao, M.; Zhang, Q.; Huang, J.; Tian, G.; Chen, T.; Qian, Z.; Wei, F. Towards high purity graphene/single-walled carbon nanotube hybrids with improved electrochemical capacitive performance. Carbon 2013, 54, $403-411$. [CrossRef]

8. Zhang, X.; Coleman, A.; Katsonis, N.; Browne, W.; Wees, B.; Feringa, B. Dispersion of graphene in ethanol using a simple solvent exchange method. Chem. Commun. 2010, 46, 7539-7541. [CrossRef]

9. Lux, F. Models proposed to explain the electrical conductivity of mixtures made of conductive and insulating materials. J. Mater. Sci. 1993, 28, 285-301. [CrossRef]

10. Tadesse, M.; Mengistie, A.; Yan, W.; Lichuan, L.; Carmen, M.; Nierstrasz, V. Electrically conductive highly elastic polyamide/lycra fabric treated with PEDOT: PSS and polyurethane. J. Mater. Sci. 2019, 54, 9591-9602. [CrossRef]

11. Tadesse, M.; Mengistie, A.; Yan, W.; Lichuan, L.; Carmen, M.; Nierstrasz, V. Effect of liquid immersion of PEDOT: PSS-coated polyester fabric on surface resistance and wettability. Smart Mater. Struct. 2017, 26, 065016. [CrossRef]

12. Lekpittaya, P.; Yanumet, N.; Grady, B.; O’Rear, E. Resistivity of conductive polymer-coated fabric. J. Appl. Polym. Sci. 2004, 92, 2629-2636. [CrossRef]

13. Terasawa, N.; Asaka, K. Performance enhancement of PEDOT:Poly(4-styrenesulfonate) actuators by using ethylene glycol. RSC Adv. 2018, 8, 17732-17738. [CrossRef]

14. Reza, M.K.; Mabrouk, S.; Qiao, Q. A review on tailoring PEDOT:PSS layer for improved performance of perovskite solar cells. Mater. Sci. Mater. Electron. 2018, 2, 1-10. [CrossRef]

15. Skrifvars, M.; Rehnby, W.; Gustafsson, M. Coating of textile fabrics with conductive polymers for smart textile applications. In Proceedings of the Welcome Ambience'08, Borås, Sweden, 2-3 June 2008; pp. 100-103.

16. Zhou, C.; Kan, C.; Matinlinna, J.; Tsoi, J. Regenerable antibacterial cotton fabric by plasma treatment with dimethylhydantoin: Antibacterial activity against S. aureus. Coatings 2017, 7, 11. [CrossRef]

17. Ahmad, I.; Kan, C.-W. Visible-light-driven, dye-sensitized TiO2 photo-catalyst for self-cleaning cotton fabrics. Coatings 2017, 7, 192. [CrossRef]

18. Saleemi, S.; Malik, S.; Syed, U.; Tanwari, A. Surface functionalization of cotton and PC fabrics using SiO2 and $\mathrm{ZnO}$ nanoparticles for durable flame retardant properties. Coatings 2020, 10, 124. [CrossRef]

19. Chakraborty, J.; Mohapatra, M.R.; Kumar, J. Differential functional finishes for textiles using graphene oxide. Res. J. Text. Appar. 2018, 22, 77-91. [CrossRef]

20. ASTM D1762-84. Standard Test Method for Chemical Analysis of Wood Charcoal; ASTM International: West Conshohocken, PA, USA, 2007.

21. ASTM E871-82. Standard Test Method for Moisture Analysis of Particulate Wood Fuels; ASTM International: West Conshohocken, PA, USA, 2013.

22. ASTM E872-82. Standard Test Method for Volatile Matter in the Analysis of Particulate Wood Fuels; ASTM International: West Conshohocken, PA, USA, 2013.

23. ASTM E872-82. Standard Test Method for Ash in Wood; ASTM International: West Conshohocken, PA, USA, 2013.

24. Molina, J. Graphene-based fabrics and their applications: A review. RSC Adv. 2016, 6, 68261-68291. [CrossRef]

25. Zhang, W.; He, W.; Jing, X. Preparation of a stable graphene dispersion with high concentration by ultrasound. J. Phys. Chem. B. 2010, 114, 10368-10373. [CrossRef]

26. Alimohammadi, F.; Gashti, M.P.; Shamei, A. A novel method for coating of carbon nanotube on cellulose fiber using 1, 2, 3, 4-butanetetracarboxylic acid as a cross-linking agent. Prog. Org. Coat. 2012, 74, 470-478. [CrossRef] 
27. Furuya, N.; Mineo, N. Preparation of a concentrated carbon black-PTFE dispersion for micro-porous layer of PEMFC. J. New Mater. Electrochem. Syst. 2007, 10, 205.

28. Akerfeldt, M.; Straat, M.; Walkenström, P. Electrically conductive textile coating with a PEDOT-PSS dispersion and a polyurethane binder. Text. Res. J. 2013, 83, 618-627. [CrossRef]

29. Tseghai, G.B.; Malengier, B.; Nigusse, A.B.B.; Van, L. Development and evaluation of resistive pressure sensors from electro-conductive textile fabric. In Proceedings of the Second International Forum on Textiles for Graduate Students, Tianjin, China, 8-10 September 2018; pp. 651-657.

30. Tseghai, G.B.; Malengier, B.; Fante, K.A.; Nigusse, A.B.; Van, L. Development of a flex and stretchy conductive cotton fabric via flat screen printing of PEDOT: PSS/PDMS conductive polymer composite. Sensors 2020, 20, 1742. [CrossRef] [PubMed]

31. BS EN ISO 105-C06. Tests for Colour Fastness Part C06: Colour Fastness to Domestic and Commercial Laundering; British Standards Institution (BSI): London, UK, 2010.

32. Kawabata, S.; Niwa, M. Objective measurement of fabric mechanical property and quality: Its application to textile and clothing manufacturing. Int. J. Cloth. Sci. Technol. 1991, 3, 7-18. [CrossRef]

33. Harrabi, L.; Dolez, P.I.; Vu-Khanh, T.; Lara, J.; Tremblay, G.; Nadeau, S.; Larivière, C. Characterization of protective gloves stiffness: Development of a multidirectional deformation test method. Saf. Sci. 2008, 46, 1025-1036. [CrossRef]

34. Omeroglu, S.; Ulku, S. An investigation about tensile strength, pilling and abrasion properties of woven fabrics made from conventional and compact ring-spun yarns. Fibres Text. East. Eur. 2007, 15, 39-42.

35. Parfen'eva, L.S.; Orlova, T.S.; Kartenko, N.F.; Smirnov, B.I.; Smirnov, I.A.; Misiorek, H.; Jezowski, A.; Muha, J.; Vera, M.C. Structure, electrical resistivity, and thermal conductivity of beech wood biocarbon produced at carbonization temperatures below $1000^{\circ} \mathrm{C}$. Phys. Solid State 2011, 53, 2398-2407. [CrossRef]

36. Nishimiya, K.; Hata, T.; Imamura, Y.; Ishihara, S. Analysis of chemical structure of wood charcoal by X-ray photoelectron spectroscopy. J. Wood Sci. 1998, 44, 56-61. [CrossRef]

37. Cohen-Ofri, I.; Weiner, L.; Boaretto, E.; Mintz, G.; Weiner, S. Modern and fossil charcoal: Aspects of structure and diagenesis. J. Archaeol. Sci. 2006, 33, 428-439. [CrossRef]

38. Bourke, J.; Manley-Harris, M.; Fushimi, C.; Dowaki, K.; Nunoura, T.; Antal, M.J. Do all carbonized charcoals have the same chemical structure? 2. A model of the chemical structure of carbonized charcoal. Ind. Eng. Chem. Res. 2007, 46, 5954-5967. [CrossRef]

39. Smith, W.C. Smart Textile Coatings and Laminates; Woodhead Publishing: Sawston, UK, 2010.

40. Atalie, D.; Tesema, A.F.; Rotich, G.K. Effect of weft yarn twist level on thermal comfort of 100 per cent cotton woven fabrics. Res. J. Text. Appar. 2018, 12,1-13. [CrossRef]

41. Tadesse, M.G.; Nagy, L.; Nierstrasz, V.; Loghin, C.; Chen, Y.; Wang, L. Low-stress mechanical property study of various functional fabrics for tactile property evaluation. Materials 2018, 11, 2466. [CrossRef] [PubMed]

42. Abbas, A.; Zhao, Y.; Zhou, J.; Wang, X.; Lin, T. Improving thermal conductivity of cotton fabrics using composite coatings containing graphene, multiwall carbon nanotube or boron nitride fine particles. Fibers Polym. 2013, 14, 1641-1649. [CrossRef]

43. Ferrero, F.; Periolatto, K. Modification of Surface Energy and Wetting of Textile Fibers, in Wetting and Wettability; InTech: Rijeka, Croatia, 2015.

44. Bonaldi, R.; Siores, E.; Shah, T. Electromagnetic shielding characterisation of several conductive fabrics for medical applications. Carbon 2010, 2, 237-245. [CrossRef]

45. Cochrane, C.; Cayla, A. Polymer-Based Resistive Sensors for Smart Textiles, in Multidisciplinary Know-How for Smart-Textiles Developers; Elsevier: Amsterdam, The Netherlands, 2013; pp. 129-153.

46. Choi, S.; Jiang, Z. A novel wearable sensor device with conductive fabric and PVDF film for monitoring cardiorespiratory signals. Sens. Actuators A Phys. 2006, 128, 317-326. [CrossRef]

47. Knittel, D.; Schollmeyer, E. Electrically high-conductive textiles. Synth. Met. 2009, 159, 1433-1437. [CrossRef]

(C) 2020 by the authors. Licensee MDPI, Basel, Switzerland. This article is an open access article distributed under the terms and conditions of the Creative Commons Attribution (CC BY) license (http://creativecommons.org/licenses/by/4.0/). 